\title{
CERRAR PODRÁ MIS OJOS... PARÁFRASIS, MÉTRICA Y HERMENÉUTICA
}

\author{
Por
}

ESTEBAN TORRE

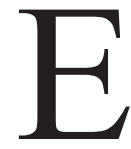

L célebre soneto de Francisco de Quevedo que lleva por título "Amor constante más allá de la muerte" ha venido siendo generalmente considerado como uno de los mejores, si no el mejor, de toda la poesía española. Al mismo tiempo, es lugar común en la crítica universitaria actual su carácter oscuro, difícil, incluso ininteligible, debido no sólo a la supuesta ambigüedad semántica del poema, sino también a su misma estructura sintáctica, que ha sido tildada de intricada y retorcida, habiendo llegado a ser conceptuada como un verdadero galimatías.

Durante muchos años, he recurrido a la lectura de este soneto, como memorable ejemplo de perfección métrica, de claridad sígnica y de equilibrio sintáctico, en mis clases de Métrica Comparada, en la Facultad de Filología de la Universidad de Sevilla. Si he de ser sincero, jamás he encontrado en él ni una partícula ambigua ni una construcción incoherente. En cuanto a la recepción por parte del alumnado, he tenido siempre la honda satisfacción de contar con un buen número de estudiantes, algunos de ellos apreciables poetas, que hacían espontáneamente una interpretación sencilla y directa del poema, corroborando mis propios comentarios. Bien es verdad que, en otros casos, la adocenada invocación a la ambigüedad y a la plurisignificación del texto literario, así como a la licitud de múltiples lecturas, hacían imposible el ejercicio de cualquier clase de rigor interpretativo.

Varios antiguos alumnos y actuales colaboradores me han animado a publicar aquellos comentarios. No es lo mismo, a 
decir verdad, la comunicación en clase, que es un vivo diálogo compartido, que la palabra escrita en solitario. Trataré, al menos, de ser breve. El texto que a continuación transcribo es el establecido por José Manuel Blecua en su excelente edición de la Obra poética de Francisco de Quevedo (Madrid, 1969), que reproduce el de la primera edición del Parnaso (Madrid, 1648) y el de la segunda (Zaragoza, 1649). Naturalmente, la ortografía y la puntuación han sido modernizadas:

Cerrar podrá mis ojos la postrera sombra que me llevare el blanco día, y podrá desatar esta alma mía hora a su afán ansioso lisonjera;

mas no, de esotra parte, en la ribera, dejará la memoria, en donde ardía: nadar sabe mi llama la agua fría, y perder el respeto a ley severa.

Alma a quien todo un dios prisión ha sido, venas que humor a tanto fuego han dado, medulas que han gloriosamente ardido,

su cuerpo dejará, no su cuidado; serán ceniza, mas tendrá sentido; polvo serán, mas polvo enamorado.

Hay que señalar que el "dejará” que aparece en el verso 12 sustituye al "dejarán” de las dos ediciones clásicas. Como hace constar el editor, se trata del alma, que dejará el cuerpo. No creo que, en cualquier caso, haya que dar demasiada importancia a la cuestión de algunas concordancias, que a veces pueden estar algo alejadas del uso actual. No era infrecuente, por ejemplo, en los siglos XVI y XVII la llamada concordancia ática, a imagen de lo que ocurre en la lengua griega, donde un sujeto en plural neutro puede concertar con un verbo en singular.

En relación con el soneto, nos proporciona José Manuel Blecua los siguiente datos bibliográficos: Amado Alonso, 
Materia y forma en poesía, Madrid, 1955, pág. 127 y sigs.; Fernando Lázaro Carreter, "Quevedo entre el amor y la muerte", en Papeles de Son Armadans, I, no. 11, 1956, pág. 145 y sigs.; Carlos Blanco Aguinaga, "Cerrar podrá mis ojos... Tradición y originalidad", en Filología, vIII, 1962, pág. 57 y sigs., y Juan Ferraté, La operación de leer y otros ensayos, Barcelona, 1962, pág. 29 y sigs. Por lo que respecta a las posibles fuentes, hace mención del trabajo de María Rosa Lida, "Para las fuentes de Quevedo", en Revista de Filología Hispánica, I, 1939, págs. 373-375, en el que se anotan algunos conceptos y rasgos estilísticos de un soneto de Luis de Camoens ("Si el fuego que me enciende consumido") y otro de Fernando de Herrera ("Llevar me puede bien la suerte mía"), así como del ensayo de Jorge Luis Borges, Otras inquisiciones, Buenos Aires, 1960, pág. 61, en donde se señala un antecedente en Propercio, Eleg. 1, 19: «Ut meus oblito pulvis amore jacet». Hay errata, por cierto, en la cita: no es jacet, sino uacet. He aquí, en efecto, el aludido dístico de Propercio: «Non adeo leuiter noster puer haesit ocellis / ut meus oblito puluis amore uacet». Se podría traducir así: "No se pegó a mis ojos nuestro niño [Cupido] tan débilmente / que mis cenizas puedan quedar vacías del olvidado amor".

A los trabajos recogidos por Blecua, habría que añadir algunos otros, entre los que cabe destacar los siguientes: Francisco de Blas, "La ruptura del lenguaje en Cerrar podrá mis ojos, de Quevedo", en Explicación de textos literarios, 14, 2, 1985, págs. 11-24; Maurice Molho, "Sobre un soneto de Quevedo: 'Cerrar podrá mis ojos la postrera'. Ensayo de una lectura literal", en Compás de Letras, 1, 1992, pags. 124-140, y Pablo Jauralde Pou, "Cerrar podrá mis ojos la postrera...", en Revista de Filología Española, t. 1, XXVII, fasc. $1^{\circ} .2^{\circ}$., 1997, págs. 89-117; sin olvidar a Evaristo Correa Calderón y Fernando Lázaro Carreter, Cómo se comenta un texto literario, Salamanca, 1971, y sus numerosísimas reediciones.

Todos estos datos quedan aquí consignados a título meramente informativo, para facilitar la labor investigadora a un hipotético lector, sin que tengan en ningún caso pretensión de exhaustividad, y mucho menos espíritu de polémica. En rea- 
lidad, no hay que perder de vista el hecho de que se trata de un soneto extraordinariamente conocido y divulgado, no sólo en papel impreso, sino también en las redes electrónicas, con más de seiscientas entradas en el Google, por ejemplo, y a través de los canales de televisión, donde recientemente ha sido difundido con las monocordes galas rítmicas de la música rap. Pues bien, sin más preámbulos, he aquí mi versión parafrástica del poema:

Bien sé que he de morir. Claramente me lo hace ver la misma vida. El sueño, viva imagen de la muerte, es mi fiel e inseparable compañero. Porque sucede que, día tras día, las sombras de la noche hacen caer mis párpados, hundiéndome en el vaporoso nimbo de los sueños. Pero llegará una sombra, la postrera sombra, la negra y definitiva sombra de la muerte, que cerrará mis ojos para siempre, robándome la dulce luz del blanco día. La muerte, la mezquina, la traidora muerte, se encuentra agazapada en las tinieblas con unas ansias irreprimibles de acudir a esa cita macabra. Y llegará un instante fatídico, una hora perversa, que, para congraciarse con el afán ansioso de esa sombra de muerte, desatará violentamente los lazos de mi alma, cortará sin piedad los hilos de mi vida.

He de morir, sí, he de cruzar las aguas tenebrosas que separan esta parte -el reino de los vivos- de esa otra parte -el reino de los muertos-. Ahora bien, cuando mi alma esté ya en la ribera de esa otra parte, no por ello abandonará el ardiente recuerdo de su vida amorosa, no dejará jamás la memoria del apasionado amor en el que ardía. Ya sé que, en el momento de subir a la barca que me trasladará a la ribera de esa otra parte, he de renunciar a todo: ropas, riquezas, vitalidad, amor; porque las almas, en el reino de los muertos, ya no serán más que vagas imágenes, impasibles siluetas, incapaces de amar y de sentir. Tal es la ley que rige los destinos de los mortales. Pero, con todo, la llama de mi amor le perderá el respeto a esa severa ley, y me acompañará a lo largo de mi travesía por la laguna Estigia. Cierto es que esta llama no podrá viajar conmigo en la barca de Caronte, pero sabrá arrojarse al agua y cruzar a nado la infame laguna. El agua fría no logrará apagarla, no podrá debilitar el poderoso fuego de mi amor. 
Mi alma será arrancada cruelmente de mi cuerpo. Las partes vitales de este cuerpo -la medula de los huesos, las venas por donde circula a borbotones la cálida sangre- serán totalmente destruidas. Todo esto habrá de suceder, irremediablemente, por más que esta alma haya tenido el privilegio de haber sido recluida por el dios Eros en una dorada cárcel de amor, por más que estas venas hayan podido servir de cauce al fuego de la pasión, por más que estas medulas hayan llegado a arder gloriosamente en el clímax más alto del éxtasis amoroso.

Así ha de ser. Lo sé. Pero no lo será del todo. El alma dejará su cuerpo, sí; pero no sus impulsos, sus sentimientos, sus preocupaciones amorosas. Las venas serán reducidas a ceniza; pero esta ceniza seguirá teniendo sentido, sensaciones, vida, y será así capaz todavía de oír, de ver, de oler y de palpar. Las medulas serán tan sólo polvo, sí, residuo mínimo, leve polvareda que disipa el viento; pero con la fuerza esplendorosa de una explosión de amor y de entusiasmo, que seguirá vibrando más allá de la muerte.

Pero volvamos al poema original. Tengamos en cuenta ante todo que se trata de un poema, escrito en verso, en el que la distribución acentual, la disposición de las rimas, las simetrías y los paralelismos son elementos rítmicos imprescindibles para la percepción de los significados, máxime cuando este poema es una consumada joya de orfebrería conceptista y barroca donde nada queda al azar en un perfecto entramado de analogías y contrastes.

En el primer cuarteto, las rimas, abrazadas, emparejan el primer verso con el cuarto y el segundo con el tercero. Ahora bien, en el plano de los significados, se produce un llamativo entrecruzamiento, de tal manera que el verso primero se corresponde paralelísticamente con el tercero y el segundo con el cuarto. También los versos pares, segundo y cuarto, aparecen rítmicamente identificados por la marcada acentuación de la sílaba primera, además de la sexta y la décima:

sombra que me llevare el blanco día 
hora a su afán ansioso lisonjera

Ambos versos, al llevar acento -acento prominente- tanto en la sílaba sexta como en la primera, bien pueden ser clasificados como enfáticos. Es obvio que existen otros lugares de acentuación: la sílaba octava, en el primero de estos dos versos, y la cuarta, en el segundo. El prurito taxonómico podría complicar, hasta el infinito, la cuestión terminológica; pero no nos interesa ahora la terminología, sino la realidad de los hechos. Entre los versos pares del primer cuarteto existe una evidente similitud rítmica, que va de la mano de una fuerte afinidad sintáctica y semántica. Los versos impares también se emparejan semántica y sintácticamente, como se pone de manifiesto en el siguiente diagrama:

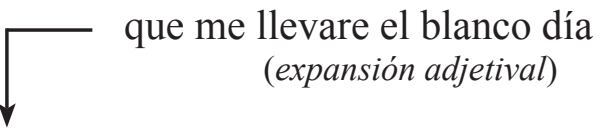

La sombra postrera (sujeto) podrá cerrar (perifr. verbal)

podrá desatar (perifr. verbal) mis ojos

(compl. directo)
[Una] hora lisonjera (sujeto)

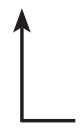

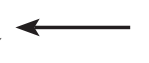

esta alma mía (compl. directo)

a su [de la sombra] afán ansioso

(compl. del adjetivo)

La expansión adjetival, la oración de relativo, si se quiere, «que me llevare el blanco día», explica cuál es exactamente esa sombra que «podrá cerrar mis ojos»: se trata de la sombra final -la muerte, definitiva noche-, que me privará para siempre de la luz del día. No hay duda de que "llevare", en la acepción de "quitar", es forma verbal transitiva de una oración subordinada donde el complemento directo 240 “el blanco día", mientras que 
"me" es complemento indirecto y "que" el sujeto, cuyo antecedente es precisamente "la postrera sombra". El Diccionario de la Lengua Española, de la Real Academia, define así esta acepción de "llevar": "Quitar algo a alguien, en general con violencia, o furtivamente». Quizás no exista en la lengua española un verbo cuyos rasgos sémicos se adapten mejor al siniestro quehacer de la muerte, la astuta, la taimada muerte, que a hurtadillas vigila el fatídico instante de asestarnos su golpe letal.

Se contrapone la sombra de la negra noche con la luz del blanco día. La oscuridad, la sombra, las tinieblas simbolizan el error y la muerte. Se trata de una constante antropológica, que hunde sus raíces en lo más profundo del inconsciente colectivo. En la mitología griega, Nix, la diosa de la noche, es hija del Caos y hermana de Erebo, que personifica las tinieblas subterráneas. Los relatos bíblicos abundan en referencias a las sombras infernales, considerándose la muerte como una región tenebrosa (Job, $38,17)$. Por el contrario, la luz del día representa el triunfo de la verdad y la vida. Tal vez el lugar donde resalta con más fuerza el contraste entre la noche -la muerte- y el día -la vida- sea el famoso soneto "Night and Death" (La noche y la muerte), del escritor sevillano José María Blanco-White. Se describe en él la situación angustiosa del primer hombre, Adán, que, deslumbrado por la paradisíaca claridad de una vida pujante y recién estrenada, recibe por vez primera la noticia de que, tras la luz del esplendoroso día, vendrán las sombras de la noche:

Mysterious Night, when the first man but knew

Thee by report, unseen, and heard thy name,

Did he not tremble for this lovely frame,

This glorious canopy of light and blue?

Yet 'neath a curtain of translucent dew

Bathed in the rays of the great setting flame,

Hesperus with the host of heaven came,

And lo! creation widened in his view.

Who could have thought what darkness lay concealed

Within thy beams, oh Sun! Or, who could find,

Whilst fly, and leaf, and insect stood revealed, 
That to such endless orbs thou mad'st us blind!

Weak man! Why to shun death this anxious strife?

If light can thus deceive, wherefore not life?

(Oh noche oscura, si por vez primera

te viera yo venir, ¿no temblaría, temiendo que esta clara luz del día, este milagro azul, se deshiciera?

Pero, si ya el lucero reverbera al caer de la tarde, y la alegría de mil estrellas nace, ¿negaría que brilla más la creación entera?

¡Quién hubiera pensado, oh noche oscura, que el propio Sol pudiera ensombrecerte, tenerte entre sus rayos escondida!

Eres gloria de paz y de hermosura.

¿Por qué temer, entonces, a la muerte?

Igual que el Sol, ¿nos cegará la vida?)

La traducción es propia, y tanto ella como el original proceden de mi Teoría de la traducción literaria, Madrid, 1994, págs. 186 y 190-191. En este soneto, el poeta viene a decirnos que la angustia adánica - nuestra angustia- no tiene razón de ser, ya que la noche esconde entre sus sombras una hermosura mayor que la del día. El cielo de la noche, cuajado de estrellas y luceros, representa en realidad la verdadera plenitud del día, si bien se encuentra transitoriamente oculto por los cegadores rayos del sol de la vida terrena, que nos impiden ver las maravillas del más allá. Desde este punto de vista, la muerte debería ser un bien apetecible y el alma inmortal habría de tener un "afán ansioso" de liberarse de las ataduras de su cuerpo terreno. Es así cómo encuentra explicación el «que muero porque no muero» de Teresa de Jesús. Del mismo modo, Fray Luis de León pudo exclamar en su oda "A Felipe Ruiz": «¿Cuándo será que pueda / libre de esta prisión volar al cielo...». Y el mismo Quevedo, en 
su silva "El sueño", expresa también sus ansias de sumirse en él como anticipo de la muerte:
¿Con qué culpa tan grave, sueño blando y suave, puede en largo destierro merecerte que se aparte de mí tu olvido manso? Pues no te busco yo por ser descanso, sino por muda imagen de la muerte.

Lupercio Leonardo de Argensola, en un soneto dedicado precisamente "Al sueño", lo tilda de "cruel" y lo considera como "imagen espantosa de la muerte". Pero, más allá del tópico del sueño como imagen de la muerte, conviene no perder de vista que, en el famoso soneto de Quevedo, el amor, constante más allá de la muerte, es un rendido súbdito de Eros, un fuego inextinguible que flamea en el meollo de los huesos y en el fluir de la sangre. El alma, enamorada, no abandonará jamás las preocupaciones carnales de su cuerpo. Nada nos hace, así pues, pensar que esta alma pueda tener un "afán ansioso" de verse privada de su cuerpo. No es el alma, sino la muerte, la postrera sombra, la furtiva y violenta señora de la noche, la que anhela llevar a cabo su tenebrosa labor. El sujeto gramatical de "podrá desatar" es "hora", la hora final, la hora fatídica, y el complemento directo "esta alma mía". El sujeto psicológico de la acción es la muerte, la sombra, con la que sintoniza esa hora final. La hora es, así, lisonjera a "su" afán ansioso. A quien lisonjea, complace y adula la hora no es precisamente al alma, sino a la muerte.

En el segundo cuarteto, al igual que en el primero, se produce un entrecruzamiento entre las sonoridades de las rimas, abrazadas, y los contenidos sémicos. El primer verso, con su alusión al viaje a la ribera de "esotra parte" se corresponde con el tercero, donde la llama del amor cruza a nado las frías aguas. El segundo verso, donde el alma persiste en la "memoria" del amor, marcha paralelo al cuarto, ya que ese recuerdo amoroso implica el olvido de la severa ley que rige el destino de los hombres: 
[Mi alma no] dejará la memoria, en donde ardía.

[Mi llama sabe] perder el respeto a ley severa.

Adviértase que «[estando] en la ribera de esa otra parte» es una cláusula absoluta: cuando mi alma, tras cruzar la laguna Estigia, esté en la ribera de esa otra parte, no dejará la memoria en la que ardía. Sería ocioso insistir en que el sujeto implícito de "no dejará" es "esta alma mía", mientras que "la memoria" es complemento directo. El alma es asimismo el sujeto de la oración adjetival "en donde [en la que] ardía". Por lo demás, la distribución acentual en este cuarteto, al igual que en los tercetos, es rica y variada, adaptándose muy bien la diversidad rítmica a la impetuosa agilidad del discurso.

Nuevamente, los contrastes: al agua fría se opone la ardiente llama; a la rígida ley, la laxa conculcación de la misma. Y el amor, en definitiva, triunfará sobre la muerte. Pero conviene insistir en el hecho de que se trata de un amor fuertemente impregnado de erotismo, muy bien anclado en la tierra: en la ribera de esta otra parte; un amor claramente carnal, que nada tiene que ver con supuestos idealismos platónicos o neoplatónicos. El alma del poeta, aun después de muerto, se llevará consigo la llama del amor. Propercio (Eleg. 2, 27) había ido aún más lejos. El verdadero amante sería capaz de arrojarse al agua desde la misma barca de Caronte, regresando a nado al reino de los vivos, a la ribera de esta otra parte:

Iam licet et Stygia sedeat sub harundine remex, cernat et infernae tristia vela ratis:

si modo clamantis revocaverit aura puellae, concessum nulla lege redibit iter.

(Y aunque ya esté sentado entre las cañas de la laguna Estigia, viendo las tristes velas del barco del infierno,

si la voz de la amada le volviera a llamar, retornaría, recorriendo un camino que la Ley no permite.)

Los textos provienen de mi libro La poesía de Grecia y Roma: Ejemplos y modelos de la cultura literaria moderna, CSICUniversidad de Huelva, 1998, págs. 200-201. Para mi versión 
española utilicé el título de "Más allá de la muerte, el amor". Propercio es también autor de otro poema (Eleg. 3, 2), al que denominé "Más allá de la muerte, la gloria" (págs. 204-205), en donde la mujer amada gozará también de la perdurable vida de la fama por el hecho de haber sido cantada por el genio inmortal del poeta:

Fortunata, meo si qua's celebrata libello! carmina erunt formae tot monumenta tuae. nam neque pyramidum sumptus ad sidera ducti, nec lovis Elei caelum imitata domus, nec Mausolei dives fortuna sepulcri mortis ab extrema condicione vacant. aut illis flamma aut imber subducet honores, annorum aut tacito pondere victa ruent. at non ingenio quaesitum nomen ab aevo excidet: ingenio stat sine morte decus.

(¡Dichosa tú, quienquiera que tú seas, si mi libro te canta! Mis poemas serán un testimonio claro de tu figura.

Ni la suntuosidad de las pirámides, alzada a las estrellas, ni la mansión de Júpiter en Élide, que es trasunto del cielo, ni la extrema riqueza del radiante sepulcro de Mausolo escapan a la cita postrera de la muerte:

el fuego o la tormenta les robarán un día su arrogancia, si al golpe de los años, vencidos por su peso, no se inclinan. Pero el nombre ganado con el genio no se pierde en el tiempo, pues la gloria del genio se prolonga más allá de la muerte.)

En "Amor constante más allá de la muerte", no aspira don Francisco de Quevedo a la vida inmortal de la fama, aunque lo cierto es que sí, que la consiguió sobradamente con este celebérrimo soneto. Tan sólo quiere dejarnos en él constancia de la extraordinaria fuerza del impulso amoroso, que llega a su máxima expresión en el grandioso remate de los tercetos. La firme estructura de los seis últimos versos viene a consolidar la totalidad del edificio poético. La rima alterna de los versos pares e impares se 
entrelaza con las secuencias correlativas de uno y otro terceto, lográndose unos sorprendentes resultados fonoestilísticos.

Nada queda al azar. Alma, venas y medulas son elementos básicos de la fisiofilosofía clásico-medieval, aún vigente en los Siglos de Oro. Cada uno de ellos, identificados por sendas oraciones adjetivas, encuentra su oportuno correlato en el segundo terceto, donde se nos dice que seguirán teniendo impulsos vitales, sensaciones, amor. Queda ahora bien claro que el alma no desea verse libre de las ataduras de la carne, sino que por el contrario anhela seguir habitando en la prisión de Eros. Al nombrar a las venas, el poeta las relaciona con el humor y con el fuego: cuatro son los humores, cuatro los elementos; y la sangre, caliente y húmeda como el aire, es precisamente el humor que circula a raudales por los vasos sanguíneos, hirviendo a borbotones con el fuego del amor, que es caliente y seco, y vehemente como la cólera. Toda una lección de fisiología, en una pincelada de once sílabas, para terminar afirmando que esas venas, aun reducidas a cenizas, continuarán sintiendo y palpitando.

Y, al final, las medulas -el meollo-del poeta enamorado serán reducidas a polvo, de acuerdo con la admonición bíblica: «Hasta que vuelvas a la tierra, pues de ella has sido tomado, ya que polvo eres y al polvo volverás» (Génesis, 3, 19). Pero incluso allí, en ese montoncillo aparentemente inerte de tierra, de polvo, de cenizas, seguirá alentando el amor. Y es que esas medulas, que una vez tuvieron la fortuna de arder gloriosamente, conservarán para siempre el calor de aquella hoguera:

me-du-las-quehan-glo-rio-sa-men-tear-di-do

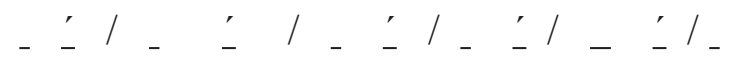

No sería aventurado decir que en este verso radica la piedra angular del edificio poético. Obsérvese que se trata de un pentámetro yámbico, en el que los acentos inciden sobre todas las 
sílabas pares; pero no en todas con la misma intensidad, sino a través de una sugestiva gradación ascendente. La escansión del verso viene a ser así un fiel trasunto del crepitar del fuego del amor, insistente, iterativo, hasta alcanzar la cúspide del glorioso ardimiento.

Medulas, no médulas. Por varias razones; pero, ante todo, por motivos de naturaleza rítmica. El poeta sevillano Juan Sierra se deleitaba, una y otra vez, en la esmerada escansión de este logrado endecasílabo. Según él, una acentuación esdrújula en el vocablo arruinaría el perfecto equilibrio del verso. Y es que, en efecto, la fuerte acentuación en la primera sílaba podría ser considerada como el punto de arranque de un endecasílabo enfático, ya que también está acentuada la sílaba sexta, o de un endecasílabo sáfico, ya que el acento afecta también a la sílaba cuarta y a la octava. Ahora bien, sucede que la escasa intensidad del acento tanto en la sílaba cuarta como en la sexta contrastaría desafortunadamente con la fuerte intensidad de la sílaba primera y de la octava. O, dicho de otro modo, a partir de la primera sílaba, enérgicamente marcada, no encontraría el oído otro fuerte apoyo acentual hasta la sílaba octava: excesivo intervalo para mantener el ritmo. No ocurre lo mismo en los dos primeros versos del terceto, en los que un marcado acento en las sílabas primera y sexta asegura su inequívo carácter de endecasílabos enfáticos.

Hay, además, sobradas razones filológicas para considerar como paroxítona la palabra medulas. Es bien sabido que medula, como vocablo culto, proviene del latín medŭlla, cuya penúltima sílaba, aunque breve por naturaleza, es larga por posición, y por lo tanto hemos de decir "medúlla". Del mismo modo, el hipotético latín vulgar medüllum habría de pronunciarse "medúllum", de donde procede el derivado popular meollo.

A comienzos del pasado siglo, don Ramón Menéndez Pidal reconocía en el Manual de gramática histórica española (párrafo 5) que ya entonces era corriente la «acentuación disparatada» de la voz médula, que se habría introducido muy tarde en el 
español, al lado de la correcta medúla, usada entre otros por Cervantes y Calderón. Por su parte, Joan Corominas atestigua en el Diccionario critico etimológico castellano e hispánico (en la voz MEOLLO) que medula es vocablo casi siempre paroxítono en la época clásica y aun todavía en poetas del siglo XVIII y principios del XIX, si bien admite que hoy está generalizada la «bárbara acentuación» esdrújula, que la Real Academia Española da ya como predominante en 1867. De hecho, en el Diccionario de la Lengua Castellana (Diccionario de Autoridades) de 1737, podemos leer repetidas veces medúla, con explícita tilde sobre la u. En las últimas ediciones del Diccionario de la Lengua Española encontramos la entrada medula o médula, que en la más reciente edición, la vigésima segunda, aparece ya como médula o medula.

No es de pensar, por tanto, que don Francisco de Quevedo pudiera haber empleado la voz esdrújula, ya que es muy poco probable que estuviera entonces en uso. En cualquier caso, prevalecen las razones rítmicas y estéticas: no encajaría la discordante fuerza inicial del esdrújulo en la suave gradación ascendente de intensidades acentuales del pentámetro yámbico en cuestión. Porque no todos los acentos tienen la misma intensidad. De ahí que, si se da el acento en sílabas contiguas, uno de ellos será predominante, como ocurre en el verso «nadar sabe mi llama la agua fría», donde la última sílaba de nadar, tónica en la palabra aislada, ve oscurecido su acento por la mayor intensidad acentual de la primera sílaba de sabe. Se trataría, en buena consecuencia, de un endecasílabo melódico. Claro que se podría mantener que la sílaba predominante es la segunda de nadar, y considerar el verso como heroico. Todo es cuestión de oído, de buen o de mal oído.

Todo es cuestión de oído, de apreciación, de sensibilidad. A los que pensamos así, a los que sentimos así, nada nos importa que nos puedan tildar de subjetivistas, o de impresionistas, o de esteticistas. Si algún lector ha tenido la paciencia de llegar hasta 
el final de estas páginas, ojalá que haya sido capaz de sentir y apreciar la fresca hermosura del imperecedero soneto de don Francisco de Quevedo, más allá de toda hojarasca erudita y de toda seca taxonomía. 